\title{
JOURNAL_RU
}

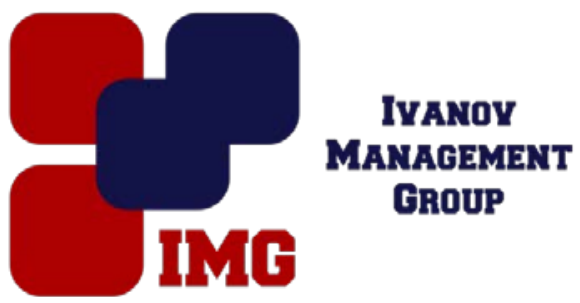

Смирнов А.В., Андрианов И.А., Суконщиков А.А., Бахтенко Е.А. Вологодский государственный университет Вологда, Россия

doi: 10.18411/lj-31-01-2017-1-15

idsp 000001:lj-31-01-2017-1-15

\section{Разработка иерархической классификации оптимизационных моделей управления цепями поставок}

Рассмотрим вопрос разработки иерархической классификации оптимизационных моделей управления цепями поставок, которая позволит уточнить области применения моделей, а также послужит концептуальной основой для выбора метода и средства решения конкретных задач планирования бизнес-процессов в цепях поставок. Вопросы классификации моделей и методов теории логистики рассматриваются в ряде работ, однако, многие попытки классификациии систематизации моделей и методов, возможных для использования в логистике, а следовательно, и определение сфер их применения, выглядят довольно хаотично. Например, в модель включаются разные по измеримости массивы информации, совершенно несопоставимые друг с другом; переменные модели очень условны; отсутствуют ограничения, которые и должны определить решаемость модели, ее реалистичность.

Проведенные исследования используемых в логистике экономикоматематических моделей и методов позволяют сделать вывод о том, что необходимо уточнение существующих классификаций. В результате предложена иерархическая классификация моделей управления цепями поставок, представленная на рис. 1 .

На верхнем уровне иерархии все модели предлагается делить «по бизнесфункциям» на два типа: модели учета издержек (транзакционные) и модели операций (аналитические).

Дальнейшая классификация разрабатывалась только для моделей операций, которые на втором уровне иерархии предлагается делить «по степени определенности» на два класса: детерминированные и неопределенные.

На третьем уровне иерархии предлагается делить модели на группы «по математическим свойствам». При этом детерминированные модели будут подразделяться на линейные, нелинейные и многоцелевые модели, а неопределенные модели - на модели принятия решений, игровые модели, модели управления запасами, модели прогнозирования, модели систем массового обслуживания и имитационные модели. 
На четвертом уровне предлагается делить все оптимизационные модели «по охватываемому временному интервалу» на статические (однопериодные) и динамические (многопериодные).

На пятом уровне предлагается деление всех статических и динамических моделей «по виду переменных» на четыре подгруппы: с непрерывными переменными, с целочисленными переменными, с булевыми переменными, с переменными смешанного типа, т.е. одна часть переменных является непрерывными, а другая часть целочисленными или булевыми. Такие модели в специальной литературе называют также моделями смешанного программирования.

На шестом уровне предлагается делить все оптимизационные модели (и статические, и динамические) «по бизнес-процессам» на следующие группы: планирования снабжения, производственного планирования, планирования аспределения, транспортные и интегрированные модели цепей поставок, в частности, транспортно-складская модель, производственно-транспортноскладская модель, интегрированная модель цепи поставок и маркетинга, интегрированная модель цепи поставок и финансового планированияи др.

В настоящее время появились новые исследования в области теории и практики проектирования нечетких систем и неопределенного программирования. В данных работах, в частности, наряду со стохастическим программированием рассматриваются также нечеткое программирование, неточное программирование, нечетко-случайное программирование, случайнонечеткое программирование и другие виды неопределенного программирования.

К построению различных моделей неопределенного программирования приводит различие в математических свойствах величин, отражающих неопределенность. Этот новый взгляд на классификацию моделей «по степени определенности» нашел отражение на рис. 1.

Классификация неопределенных моделей не представлена рис. 1, но она, по нашему мнению, должна соответствовать общепринятой классификации. Например, модели принятия решений, подразделяются «по предположениям о поведении природы» на три подгруппы: модели принятия решений в условиях определенности, модели принятия решений в условиях риска и модели принятия решений в условиях неопределенности. Модели прогнозирования подразделяются «по категориям» на причинно-следственные модели и модели временных рядов.

По нашему мнению, основных свойств базовых компонентов модели (переменных, ограничений, целевой функции) оказывается вполне достаточно для классификации большинства конкретных моделей оптимизации цепей поставок, встречающихся на практике. Представленная выше иерархическая классификация моделей управления цепями поставок, позволяет глубже понять, где применяются и как используются те или иные модели, а также служит концептуальной основой для адекватного выбора метода и средства решения конкретных задач того или иного класса. 


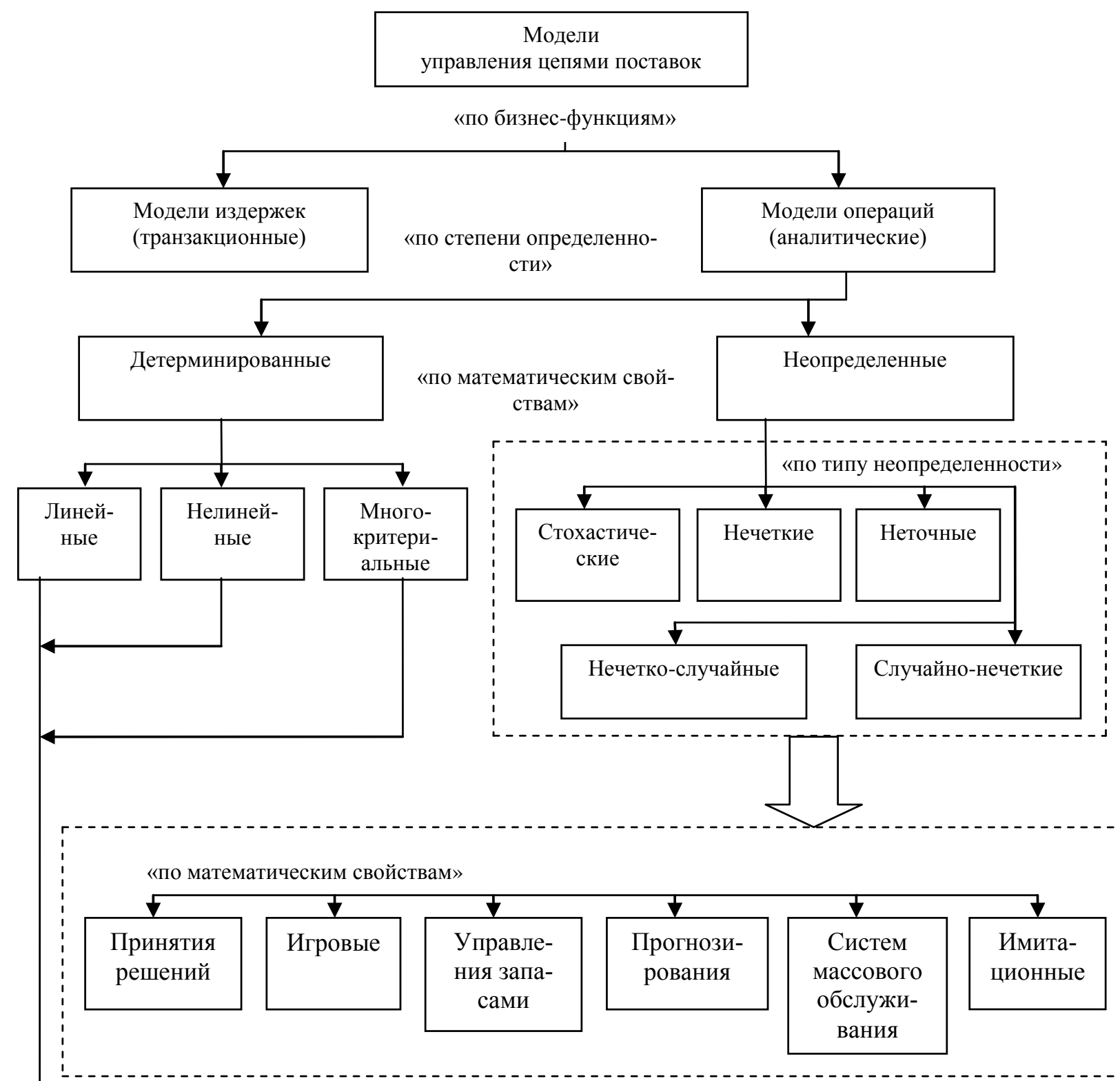

«по охватываемому временному интервалу»

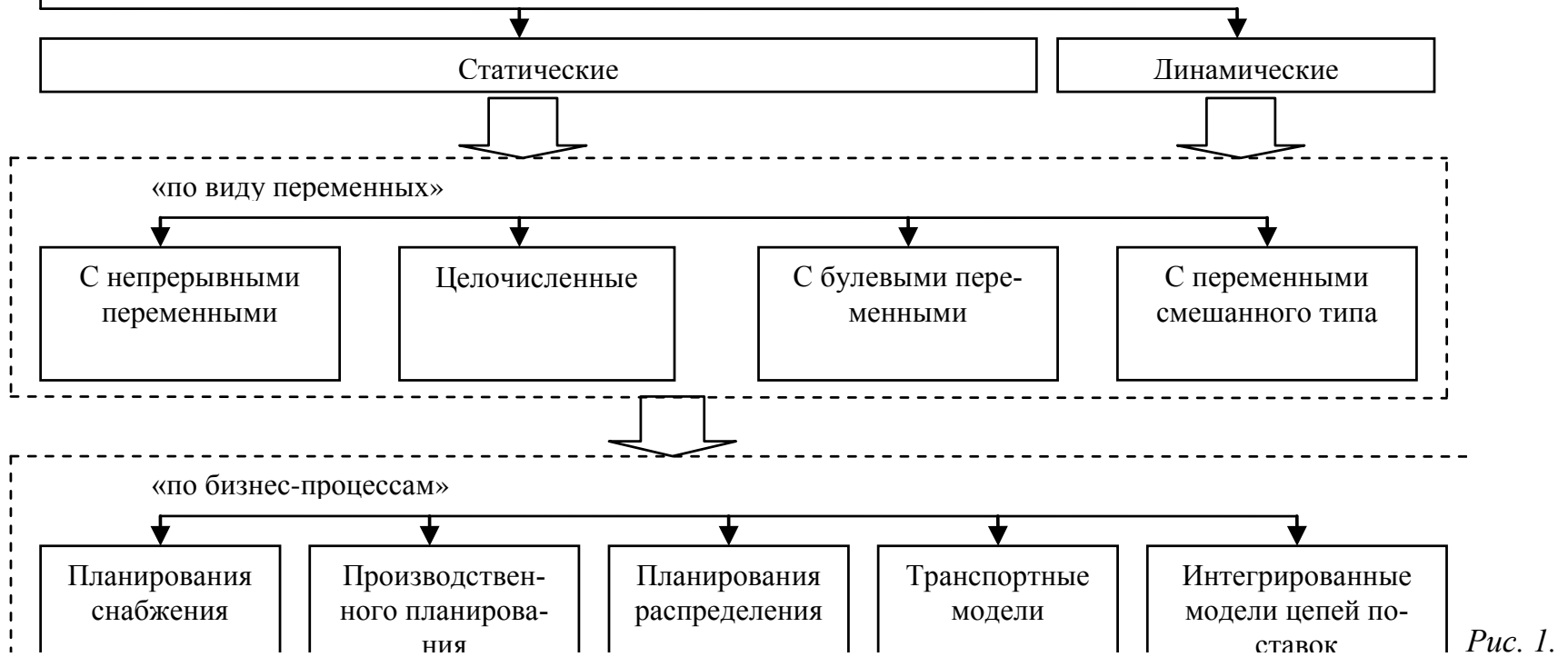

- Классификаџия оптимизацчионных моделей управления цุепями поставок 